Let's take forward the suggestions from this much needed and welcoming editorial, let's invest in the future by investing in our educationalists; remember as we all get older, we may come to thank these specialists for producing the doctor that is now providing us with excellent care.

\section{Trevor Gibbs,}

Visiting Professor in Medical Education and Primary Care, Ukraine National Medical Academy of Postgraduate Medicine, Kiev, Ukraine.E-mail: tjg.gibbs@gmail.com

\section{REFERENCE}

1. Rees PJ, Stephenson AE. The future of medical education in the UK. Br J Gen Pract 2010; 60(580) 795-796.

DOI: 10.3399/bjgp10X544131

\section{Medical certification: is it in the patient's best interest?}

The paper on 'work-related sickness absence negotiations: GPs' qualitative perspectives" provided invaluable insight into the feelings and perceptions of GPs who are asked by their patients to provide medical certification regarding absence from work. It highlights the vast differences between GPs concerning the provision of medical certification.

The paper also highlighted that several GPs felt that it would be detrimental to the doctor-patient referral if the medical certificate was not provided. ${ }^{1}$ However, the question remains 'if a patient was to ask for a therapy that would not be in their best interests should we as GPs still go ahead and prescribe it?' For this reason when issuing a medical certificate would it not be wise for the consulting GP to ask themselves 'am I doing what is in my patient's best interest?'

Several studies have re-enforced the beneficial effects of work and the adverse effects of prolonged unemployment. ${ }^{2,3}$ The association of unemployment and an increased Framingham Risk Score, and subsequently, the heightened risk of developing cardiovascular disease has been documented in studies conducted in unemployed men in Poland. ${ }^{4}$ In addition to the physical illness associated with longterm unemployment, the psychological consequences are also of considerable significance. $^{5}$

Platt et al established that there was a positive correlation between long-term unemployment and suicide rates among men in Italy during the period of 1977-1987. ${ }^{6}$ This positive correlation was also supported by a recent study of unemployed men in Japan.

Although in New Zealand this increase in suicide risk has been attributed to confounding factors, ${ }^{8}$ one cannot argue the beneficial effects of employment on both physical and psychological health.

Therefore, a healthier population can in turn result in a decrease in surgery visits, hospital admissions, and a reduced strain on limited financial resources with an increase in economic productivity.

Increased sickness absence from work can also result in a greater risk of unemployment. ${ }^{9}$ The recent changes to the medical certificate have provided GPs with several options as an alternative to 'you are not fit to work', helping to ensure patients remains in some form of employment. In addition to this there is evidence to suggest that a graded return to work can increase the probability of the patient gaining and remaining in employment. ${ }^{10}$

Although the present system of medical certification has many flaws, the realisation that employment has beneficial effects on health have been known for some time and should remain foremost when making a decision regarding time off work.

Perhaps it would be in patients' and GPs' best interest if this role was taken away from GPs, thereby minimising the possibility of a conflict of interest and reducing the probability of many a dilemma faced by GPs when issuing medical certificates.

Ultimately, it is the authors' view that a medical certificate should be seen as any other medicine that is prescribed. Therefore, it should only be issued if it is truly in the patient's best interests thereby ensuring beneficence and non-

maleficence, so that two of the four pillars of medical ethics are respected at all times.

\section{Hardeep Bhupal,}

Associate GP, Botwell Medical Centre, Hayes, Middlesex.

E-mail: hkbhupal@hotmail.com

\section{REFERENCES}

1. Money A, Hussey L, Thorley K, et al. Work-related sickness absence negotiations: GPs' qualitative perspectives. Br J Gen Pract 2010; 60(579): 721-728.

2. Graetz B. Health consequences of employment and unemployment: longitudinal evidence for young men and women. Soc Sci Med 1993; 36(6): 715-724.

3. Leeflang RL, Klein-Hesselink DJ, Spruit IP. Health effects of unemployment - II. Men and women. Soc Sci Med 1992; 34(4): 351-363.

4. Kozieł S, Lopuszańska M, Szklarska A, Lipowicz A. The negative health consequences of unemployment: the case of Poland. Econ Hum Biol 2010; 8(2): 255-260.

5. Latif E. Crisis, unemployment and psychological wellbeing in Canada. J Policy Model 2010; 32(4): 520-530.

6. Platt S, Micciolo R, Tansella M. Suicide and unemployment in Italy: description, analysis and interpretation of recent trends. Soc Sci Med 1992; 34(11): 1191-1201.

7. Kuroki M. Suicide and unemployment in Japan: evidence from municipal level suicide rates and agespecific suicide rates. J Socio Econ 2010; 39(6): 683-691.

8. Fergusson DM, Boden JM, Horwood LJ. Unemployment and suicidal behavior in a New Zealand birth cohort: a fixed effects regression analysis. Crisis 2007; 28(2): 95-101.

9. Hesselius P. Does sickness absence increase the risk of unemployment? J Socio Econ 2007; 36(2): 288-310.

10. Høgelund J, Holm A, McIntosh J. Does graded returnto-work improve sick-listed workers' chance of returning to regular working hours? J Health Econ 2010; 29(1): 158-169.

DOI: 10.3399/bjgp10X544140

\section{GP obstetrics}

David Jewell's lament for GP obstetric services is clearly heart-felt and he makes some valid points. ${ }^{1}$ But I am far from convinced that his sense of loss, particularly for GP intrapartum care, is shared by the majority of current practising GPs. Moreover, he makes a number of assertions that are open to critical analysis.

It has become common place to blame 
the 2004 change in out-of-hours care arrangements for a variety of perceived deficiencies in UK general practice. Jewell cites these changes as one of the reasons for GPs giving up intrapartum care but he provides no evidence to back up this claim. In reality, in my locality at least, GP intrapartum care disappeared long before 2004.

While it's true to say that I miss my previous level of involvement in antenatal care, I am more than happy to accept community midwives as an integral part of the primary care team, and to delegate the care of normal pregnancies and deliveries to them. This is where their field of expertise lies. GPs now need to focus their attention on higher risk pregnancies rather than carrying out routine, but unnecessary, monthly antenatal reviews of healthy, uncomplicated pregnancies.

Jewell focuses on the Confidential Enquiry into Maternal and Child Health, ${ }^{2}$ highlighting thromboembolism, cerebral haemorrhage, and mental health issues in particular. While there is no place for complacency, he does not put these areas of concern into context and I think he over-emphasises the case. In reality, as the Enquiry clearly states, 'maternal deaths are extremely rare in the UK, and the proportion of the very small number of mothers whose care was less than optimal has not increased for many years'. There has been no significant statistical change in the numbers since 1985 (when, presumably, GPs were more heavily involved in obstetric care) but again, as the Enquiry makes clear, that fact has to be seen in context - 'the failure of the maternal mortality rate to decline has to be viewed in the light of both documented and undocumented changes in the childbearing population. Although there have been positive changes, there have also been increases in the numbers of women whose social circumstances and health put them at risk of maternal death'.2

According to the Enquiry, thromboembolism is very uncommon, occurring in approximately 13 per 100000 maternity cases. Fatal pulmonary embolism is even rarer with an incidence of 2 per 100000 pregnancies. In my practice we have around 50 maternity cases per annum from a practice population of 5200 . This means we will see one case of fatal pulmonary embolism in a maternity case every 1000 years! Of course, that fatal case could occur today, tomorrow, or next week but it is hardly grounds for panic. In reality the combination of road traffic accidents, murder, and non-obstetric cancer account for about the same number of maternity deaths.

Training is important and Jewell is right to emphasise that and to bemoan any reduction in training. But the Confidential Enquiry also has things to say about training. It makes a number of recommendations:

All clinical staff must undertake regular written, documented, and audited training for:

- the identification and management of serious medical and mental health conditions that, although unrelated to pregnancy, may affect pregnant women or recently delivered mothers;

- the early recognition and management of severely ill pregnant women and impending maternal collapse;

- the improvement of basic, immediate, and advanced life support skills. A number of courses provide additional training for staff caring for pregnant women; and

- staff also need to recognise their limitations and to know when, how, and whom to call when assistance is required. ${ }^{2}$

Neither Jewell nor the Enquiry demonstrate the mechanisms by which such a level of training can be delivered clearly and consistently in primary care. Moreover, it is widely recognised that under-utilised skills deteriorate within weeks or months of training. Unless the training is provided on a recurring basis how can GPs hope to maintain the skills required for intrapartum care with only one or two deliveries a year? Also, as was recently pointed out in the $B M J,{ }^{3}$ a push towards home births or births in midwifeled units may not be without increased risks (particularly in terms of neonatal mortality).

I know from the anecdotal experience of my own locality that the majority of GPs heaved a quiet sigh of relief when they were no longer faced with the prospect of intrapartum care.

\section{Steve McCabe,}

Portree Medical Centre, Portree, Skye, IV51 9PE. E-mail: steveborve@hotmail.com

\section{Conflict of interest}

A remote, rural GP formally involved with community intrapartum care.

\section{REFERENCES}

1. Jewell D. Jumping (or being pushed) from maternity care. Br J Gen Pract 2010; 60(580): 799-800.

2. Confidential Enquiry into Maternal and Child Health. Saving mothers' lives: reviewing maternal deaths to make motherhood safer: 2003-2005. The seventh report of the confidential enquiries into maternal deaths in the United Kingdom. London: CEMACH, 2007.

3. Tuffnell D. Place of delivery and adverse outcomes. BMJ 2010; 341: c5560.

DOI: 10.3399/bjgp10X544159 